\title{
KONDISI SANITASI TERMINAL MABU'UN KABUPATEN TABALONG
}

\author{
Tien Zubaidah, Rusinta \\ Poltekkes Kemenkes Banjarmasin Jurusan Kesehatan Lingkungan \\ Jl. H. M. Cokrokusumo No. 1 A Kota Banjarbaru \\ Email: arrasyid.hanif@gmail.com
}

\begin{abstract}
Sanitary Conditions Terminal Mabu'un Tabalong. One impact of the terminal is the possibility of disease transfer and transmission of vector -borne diseases through the means of conveyance. This study aims to determine the sanitary conditions in the Terminal Mabu'un Tabalong. Data were collected in the form of frequency tabulation then analyzed descriptively and compared with the requirements according to DEPKES DITJEN . PPM and PLP 1999. The result show that the sanitation in Terminal Mabu'un Tabalong including healthy feasible for terminal infrastructure with a yield of 86.0 percent of $\leq 75$ percent of the specified conditions. However there are several aspects that need attention sanitation ie from outside environmental health aspects, sanitation space and buildings, sanitary facilities and food sanitation. Efforts are being made to improve sanitation in Terminal Mabu'un Tabalong like doing cleaning around the terminal, power supply cleaning service for the reception area, increasing the number of bins, sanitary inspection terminals and provide counseling .
\end{abstract}

Keywords : Health environment, sanitation value , sanitation terminal

\begin{abstract}
Abstrak: Kondisi Sanitasi Terminal Mabu'un Tabalong. Salah satu dampak kegiatan terminal adalah kemungkinan terjadinya perpindahan penyakit dan penularan penyakit yang ditularkan oleh vector yang melalui alat angkut. Tujuan penelitian ini adalah untuk mengetahui kondisi sanitasi di Terminal Mabu'un Kabupaten Tabalong. Data penelitian dikumpulkan dalam bentuk tabulasi frekuensi kemudian dianalisis secara deskriptif dan dibandingkan dengan persyaratan menurut Depkes RI DITJEN. PPM dan PLP Tahun $1999 . \quad$ Hasil penelitian menunjukkan bahwa sanitasi di Terminal Mabu'un Kabupaten Tabalong termasuk laik sehat untuk prasarana terminal dengan hasil sebesar 86,0 persen dari $\leq 75$ persen dari syarat yang ditentukan. Namun ada beberapa aspek sanitasi yang perlu mendapat perhatian yaitu dari aspek penyehatan lingkungan luar, penyehatan ruang dan bangunan, fasilitas sanitasi dan penyehatan makanan. Upaya yang dilakukan untuk meningkatkan sanitasi di Terminal Mabu'un Kabupaten Tabalong seperti melakukan pembersihan di sekitar terminal, penyediaan tenaga cleaning service untuk ruang tunggu, menambah jumlah tempat sampah, melakukan pemeriksaan sanitasi terminal serta memberikan penyuluhan.
\end{abstract}

Kata Kunci : Penyehatan lingkungan, nilai sanitasi, sanitasi terminal.

\section{Pendahuluan}

Peranan transportasi dewasa ini memiliki peranan penting dan strategis dalam bidang pembangunan, maka perencanaan dan pengembangannya perlu disusun dalam kesatuan sistem yang terpadu. Untuk dapat terlaksananya keterpaduan intra dan antar moda dengan lancar dan tertib, sehingga ditempat-tempat tertentu perlu dibangun dan diselenggarakan terminal.

Terminal bukan merupakan sebagai komponen fungsional utama dari sistem, tetapi sering juga merupakan prasarana 
yang memerlukan biaya sangat besar dan merupakan titik tempat terjadinya kemacetan. Terminal merupakan titik simpul dalam jaringan transportasi jalan juga sebagai salah satu pusat pelayanan umum, juga merupakan tempat pengendalian, pengawasan, pengaturan serta pengoperasian lalu lintas yang akhirnya merupakan prasarana untuk kelancaran penumpang dan barang. Disisi lain terminal mempunyai keterkaitan dengan unsur tata ruang yang mempunyai peranan penting bagi efisiensi kehidupan kota $^{1}$

$\begin{array}{lcr}\text { Terminal dalam } & \text { pencapaian } \\ \text { pembangunan } & \text { nasional } & \text { peranan }\end{array}$
transportasi memiliki posisi yang penting dan strategi dalam pembangunan, maka perencanaan dan pengembangannya perlu ditata dalam satu kesatuan sistem yang terpadu. Untuk terlaksananya keterpaduan intra dan antar moda secara lancar dan tertib maka ditempat-tempat tertentu perlu dibangun dan diselenggarakan terminal ${ }^{2}$

Terminal bukan saja merupakan komponen fungsional utama dari sistem, tetapi juga sering merupakan prasarana yang memerlukan biaya yang besar dan titik di mana kongesti (kemacetan) mungkin terjadi. Dampak lain yang mungkin terjadi dari kegiatan terminal adalah kemungkinan terjadinya perpindahan penyakit dan penularan penyakit yang ditularkan oleh vector yang melalui alat angkut selain segi kesehatan, aspek kenyamanan dan keamanan juga mengambil peranan penting 3

Penyehatan sarana dan bangunan umum merupakan sub sistem, dalam pembangunan kesehatan bertujuan untuk melindungi masyarakat agar terhindar dari kejadian penyakit serta kecelakaan, dengan demikian diharapkan sarana dan bangunan dapat memenuhi kebutuhan fisiologis, psikologis serta dapat mencegah penularan penyakit dan terjadinya kecelakaan ${ }^{4}$.

Berdasarkan hasil penelitian yang di lakukan oleh Maulana Fazerin MS (2011) ${ }^{5}$ pada Terminal di Kota Barabai menunjukan bahwa sanitasi pada terminal tersebut tidak memenuhi syarat untuk prasarana angkutan umum/darat dengan hasil didapat 55,2 persen, dari syarat yang ditentukan yaitu $\geq 75$ persen. Hasil tersebut menunjukan bahwa dari semua aspek sanitasi masih kurang yaitu dari penyehatan lingkungan luar, penyehatan ruang dan bangunan, fasilitas sanitasi, kenyamanan dan keselamatan serta penyehatan makanan. Penelitian yang dilakukan oleh Anissa Veramida (2012) ${ }^{6}$, pada Terminal Stagen Kabupaten Kotabaru didapat hasil pemeriksaan sebesar 69,8 persen. Hasil tersebut termasuk dalam kriteria tidak memenuhi syarat untuk prasarana terminal. Dari semua aspek yang tidak memenihi syarat yaitu kondisi lingkungan terminal, kondisi ruang dan bangunan terminal, dan fasilitas sanitasi.

Secara umum tujuan umum penelitian ini adalah untuk mengetahui kondisi sanitasi Terminal Mabu'un Kabupaten Tabalong meliputi kondisi penyehatan lingkungan luar Terminal, kondisi penyehatan ruang tunggu dan bangunan serta menentukan nilai sanitasi Terminal Mabu'un.

Diharapkan penelitian ini dapat dijadikan sebagai masukan untuk pembinaan dan pengawasan terus-menerus kualitas kesehatan lingkungan di Terminal Mabu'un.

\section{Metode Penelitian}

Penelitian ini merupakan penelitian deskriptif, data-data dikumpulkan pada observasi awal, wawancara dan selanjutnya dianalisis sehingga menggambarkan kondisi di terminal.

Objek penelitian pada penelitian ini adalah terminal termasuk gedung terminal dan sekitarnya, tidak termasuk diluar pagar terminal. Variabel yang diteliti meliputi penyehatan lingkungan luar terminal, penyehatan ruang tunggu dan bangunan terminal dan fasilitas sanitasi yang tersedia di terminal.

Pengumpulan data dilakukan melalui pengamatan (observasi) yang dilakukan pada penyehatan lingkungan luar terminal, penyehatan ruang tunggu dan bangunan terminal, dan fasilitas sanitasi serta dilakukan pengukuran untuk tingkat kebisingan.

Selanjutnya data diolah dalam bentuk tabulasi frekuensi kemudian dianalisis secara deskriptif dan disandingkan dengan 
persyaratan menurut Depkes RI DITJEN.PPM Dan PLP Tahun 1999 tentang Formulir Pemeriksaan Kesehatan Lingkungan (Inspeksi Sanitasi Prasarana Angkutan Umum/Darat) ${ }^{7}$.

\section{Hasil dan pembahasan}

Terminal Mabu'un Kabupaten Tabalong yang terletak di Jalan Mabu'un Raya Km 5 Kota Tanjung samping spbu, masuk dalam wilayah Kecamatan Murung pudak Kabupaten Tabalong. Didirikan pada tahun 1994 dan kemudian diresmikan pada tahun 1995 dengan terminal tipe $C$ yang melayani kendaraan umum untuk angkutan dalam pedesaan. Luas area terbuka pada terminal Keramat Barabai ini adalah $10.000 \mathrm{~m}^{2}$ sedangkan untuk area tertutupnya adalah $90 \mathrm{~m}^{2}$. Terminal Mabu'un Kabupaten Tabalong ini adalah milik pemerintah daerah Kabupaten Tabalong yang dikelola oleh Dinas Kabupaten Tabalong dengan jumlah karyawan 12 orang yang bertugas di terminal.

Penyehatan Lingkungan Luar

Lokasi Terminal Mabu'un Kabupaten Tabalong letaknya sangat strategis dan mudah dijangkau. Lokasi Terminal Mabu'un Kabupaten Tabalong tidak terletak di daerah banjir, tetapi tidak terhindar dari pencemaran kimia, fisik maupun bakteri. Bahan kimia dan partikel debu didapat dari hasil buangan gas kendaraan bermotor.

Ketentuan untuk lokasi menurut KEPMENKES Nomor: 829 /Menkes /SK / VII / 1999 tentang persyaratan perumahan dan permukiman ${ }^{8}$ mensyaratkan sebaiknya harus terhindar dari pencemaran kimia, fisika, bakteri dan tidak terletak di daerah banjir.

Jika lokasi tidak terhindar dari pencemaran bisa menyebabkan keracunan dan gangguan kesehatan, selain itu lokasi yang terletak daerah banjir akan mengganggu para penumpang ,fasilitas yang ada di terminal, sehingga aktifitas di terminal akan terganggu dan memungkinkan terjadinya penularan penyakit.

Lingkungan di luar bangunan Terminal Mabu'un Kabupaten Tabalong kondisinya kurang bersih terdapat sampah, sehingga memungkinkan sebagai tempat berkembang biak binatang pengganggu dan tidak dapat mencegah masuknya binatang pengganggu.

Kondisi lingkungan di luar bangunan sebaiknya harus bersih, tidak memungkinkan sebagai tempat berkembang biak binatang pengganggu, serta dapat mencegah masuk/berkembang biak binatang penggangu. Jika lingkungan luar bangunan kurang bersih dan banyak sampah akan memungkinkan binatang pengganggu dan menyebabkan penularan penyakit ${ }^{9}$.

Tempat/halaman parkir kendaraan di Terminal Mabu'un Kabupaten Tabalong kondisinya kurang bersih, pada sebagian tempat parkir/halaman kendaraan terdapat bagian yang tidak rata dan berlobang. tetapi halaman parkir tidak becek/berdebu.

Tempat/halaman parkir kendaraan menurut persyaratan kesehatan pada terminal adalah terdapat tempat parkir kendaraan umum yang bersih, tidak terdapat sampah berserakan, genangan air dan lain-lain ${ }^{10}$.

Penyehatan Ruang dan Bangunan

Tempat pemberangkatan/tempat kedatangan pada Terminal Mabu'un Kabupaten Tabalong kurang bersih karena terdapat beberapa sampah tetapi lantai kedap air, tempat pemberangkatan/tempat kedatangan tidak rata karena lantai ada yang berlobang dan tidak licin.

Tempat pemberangkatan atau tempat kedatangan harus bersih, lantai kedap air, rata, dan tidak licin. Sampah yang berserakan bisa menimbulkan penularan penyakit dan lantai yang tidak rata berlobang akan mengganggu aktivitas terminal yaitu pada tempat pemberangkatan/tempat kedatangan, jika tempat pemberangkatan atau tempat kedatangan kurang bersih akan memungkinkan tempat perkembang biaknya lalat dan penularan penyakit? ${ }^{7}$.

Lantai pada ruang tunggu Terminal Mabu'un Kabupaten Tabalong terlihat kuat, terlihat kuat lantai kedap air, tidak licin, dan mudah dibersihkan tetapi lantai terminal 
terdapat debu. Lantai ruang tunggu Menurut persyaratan kesehatan pada terminal harus kuat, bersih, kedap air, rata, tidak licin dan mudah dibersihkan ${ }^{10}$.

Tempat sampah yang terdapat di ruang tunggu terminal tersedia 1 buah dan tidak dilengkapi dengan penutup. Tempat sampah seharusnya terbuat dari bahan yang kuat, kedap air dan ringan di setiap radius radius 10 meter dan dilengkapi dengan penutup, karena jika tempat sampah tidak dilengkapi dengan penutup akan menjadi tempat berkembang biaknya lalat dan memungkinkan terjadinya penularan penyakit selain itu bisa menjadi tempat sarang nyamuk ${ }^{4,11}$.

\section{Fasilitas Sanitasi}

Penyediaan air bersih pada terminal tersedia cukup untuk setiap kegiatan karena pada terminal terdapat tandon yang berisi 1000 liter, dilihat dari kondisi fisik sarana air bersih dalam keadaan baik dan kualitas air bersih tidak secara periodik.

Menurut peraturan KEPMENKES Nomor: 829 /Menkes /SK / VII / 1999 untuk penyediaan air bersih adalah tersedia cukup air bersih sepanjang waktu dengan kualitas memenuhi persyaratan kesehatan. Penyediaan air bersih yang tidak tersedia cukup pada setiap kegiatan akan menimbulkan berbagai masalah kesehatan terminal selain itu ketidak nyamanan yang dirasakan oleh pengunjung terminal, selain itu perlunya kualitas air yang memenuhi syarat agar air bersih yang dipakai sudah aman untuk digunakan'8.

Terminal Mabu'un memiliki 2 toilet dan dilengkapi dengan kamar mandi, toilet dalam keadaan kotor. Kondisi toilet berbau, toilet dilengkapi dengan septic tank dan tidak dihubungkan dengan sistem pengolahan air limbah/IPAL. Toilet menurut persyaratan kesehatan terminal harus tersedia minimal 2 toilet, bersih dan tidak berbau, toilet dihubungkan dengan sisitem pengolahan air limbah/IPAL, septic tank. jumlah 1 buah urinoir untuk setiap 1250 pengunjung pada suatu saat, dengan jumlah minimal 2 buah $^{10}$. Toilet yang kotor dan berbau yang tidak dijaga kebersihannya menjadi sarana penularan penyakit misal penyakit kulit, cacing yang ditularkan oleh vektor ${ }^{11}$.

Tempat sampah di ruang terbuka yang tersedia di ruang terbuka terminal terdapat 1 buah tempat sampah dalam keadaan baik setiap radius 20 meter dan tempat sampah terbuat dari bahan yang kuat, anti karat, tetapi tidak ringan, mudah dibersihkan serta tidak dilengkapi dengan penutup.

Tempat penampungan sampah sementara di Terminal Mabu'un Kabupaten Tabalong terletak pada lokasi yang mudah dijangkau oleh petugas, tersedia air pembersih yang cukup, tidak permanen, disekitarnya kurang bersih, lembab dan kedap air, sehingga memungkinkan tempat perkembang biaknya serangga dan tikus tetapi sampah dibuang/diangkut $<3$ hari sekali oleh petugas kebersihan.

Tempat sampah di ruang terbuka harus tersedia minimal 1 buah pada setiap radius 20 meter, terbuat dari bahan anti karat, ringan dan mudah dibersihkan serta dilengkapi dengan penutup. Tempat sampah yang tidak dilengkapi dengan penutup memungkinkan binatang pengganggu masuk dan berkembang biak sehingga memungkinkan sebagai pembawa penularan penyakit. Tempat penampungan sampah sementara sesuai persyaratan kesehatan terminal tersedia tempat pengumpulan sampah sementara sebelum dibuang dan harus tertutup serta kedap air, karena jika tempat penampungan sampah sementara di sekitarnya kurang bersih akan menimbulkan tempat berkembang biaknya serangga dan bisa menularkan penyakit ${ }^{4,11}$.

Kenyamanan dan Keselamatan

Pengukuran untuk tingkat kebisingan pada ruang tunggu Terminal Mabu'un Kabupaten Tabalong diambil sebanyak 3 waktu yaitu pada pagi hari, siang hari dan sore hari dengan hasil sebagai berikut :

Hasil pengukuran menunjukkan 56,2 dBA pada pagi hari, 58,2 dBA pada siang hari dan sore hari sebesar 58,0 dBA.

Tabel 1. Hasil rata-rata pengukuran tingkat kebisingan di ruang tunggu Terminal Mabu'un Kabupaten Tabalong Tahun 2013 


\begin{tabular}{cccc}
\hline No & Waktu Pengambilan & Intensitas (dBA) & Standar \\
\hline 1 & Pagi & 56,0 & \\
2 & Siang & 58,2 & $60,0 \mathrm{dBA}$ \\
3 & Sore & 58,0 & \\
\hline
\end{tabular}

Kebisingan menurut PERMENKES No. 718/ Men/ Per/ XI/ 1987 kebisingan maksimum dianjurkan $60 \mathrm{dBA}$ dan diperbolehkan $70 \mathrm{dBA}$, jika melebihi dari standar tersebut membahayakan kesehatan dan efek terhadap pendengaran ${ }^{12}$.

Sirkulasi udara pada Terminal Mabu'un Kabupaten Tabalong cukup baik, tidak berbau (terutama gas $\mathrm{NH}_{3}$ dan/atau $\mathrm{H}_{2} \mathrm{~S}$ ). karena disebabkan oleh asap kendaraan bermotor.

Menurut persyaratan rumah sehat ventilasi adalah udara yang masuk harus udara bersih, tidak dicemari oleh asap dari sampah, pabrik, knalpot, debu dan lain-lain. Aliran udara juga tidak menyebabkan orang masuk angin. Ventilasi menimbulkan sedikit bau yang ditimbulkan dari kendaraan bermotor, efek ini tidak baik bagi kesehatan jika terhirup ${ }^{10}$.

Terminal Mabu'un tersedia alat pemadam kebakaran dalam jumlah yang cukup, terletak pada lokasi yang mudah dijangkau oleh petugas, tetapi tidak ditera secara periodik oleh petugas pemadam kebakaran hanya oleh petugas terminal saja. Alat pemadam kebakaran harus tersedia dalam jumlah yang cukup, terletak pada lokasi yang mudah dijangkau oleh petugas, dan ditera secara periodik oleh petugas pemadam kebakaran? ${ }^{7}$.

\section{Penyehatan Makanan}

Berdasarkan hasil observasi, kondisi fisik penjamah makanan yang berjualan di Terminal Mabu'un Kabupaten Tabalong tidak berpenyakit kulit, mata, ISPA. Penjamah berperilaku sehat dan berpakaian bersih, utuh/tidak sobek.

Penjamah makanan yang tidak menerapkan prinsip hygiene dan sanitasi dalam pengelolaan makanan dapat menimbulkan keracunan, diare, dan sebagainya bagi konsumen ${ }^{13}$.

Penjamah makanan dalam memilih bahan makanan yang baik dan segar tetapi bahan makanan mentah tidak disimpan pada tempat yang bersih dan sehat. Makanan jadi dalam keadaan baik dan sehat, makanan jadi tidak di tempatkan pada wadah yang terbuat dari bahan beracun ( $\mathrm{Cd}, \mathrm{Pb}, \mathrm{Cu}$, dll). Bahan makanan mentah harus dalam keadaan baik dan segar serta bahan makanan mentah disimpan pada tempat yang bersih dan sehat. Jika bahan makanan tidak disimpan pada tempat yang bersih akan menimbulkan diare, keracunan dan lainnya.

Peralatan makanan dan minuman dalam keadaan bersih, tetapi terlihat beberapa peralatan makan/minum dalam keadaan retak/pecah, serta peralatan yang siap pakai disimpan pada tempat yang bebas dari pencemaran. Peralatan makan/minum harus dalam keadaan bersih, tidak retak/gopel/pecah dan disimpan pada tempat yang bebas dari pencemaran, tetapi pada warung makan terminal terlihat ada beberapa peralatan makan/minum yang retak, hal ini bisa mengganggu pada saat menikmati makanan dan terjadinya kecelakaan dalam memakai peralatan makan/minum ${ }^{13}$.

Nilai Sanitasi Prasarana Angkutan
Umum/Darat
Berdasarkan hasil perhitungan meliputi penyehatan lingkungan luar, penyehatan ruang dan bangunan serta ketersediaan fasilitas sanitasi, diperoleh nilai sebesar 86,0 persen. Ini artinya nilai sanitasi Terminal Mabu'un termasuk pada kategori laik sehat $(\geq 75 \%)$. Walaupun termasuk kategori laik sehat, di Terminal Mabu'un masih terdapat beberapa aspek penyehatan yang perlu mendapat perhatian.

\section{Kesimpulan}

Nilai sanitasi Terminal Mabu'un Kabupaten Tabalong didapat sebesar 86, 0 $\%$. Hasil tersebut termasuk dalam kriteria laik sehat untuk prasarana terminal yaitu $\geq$ 
$75 \%$, namun ada beberapa aspek yang perlu mendapat perhatian yaitu lingkungan luar Terminal Mabu'un Kabupaten Tabalong masih kurang bersih terdapat sampah, memungkinkan tempat berkembang biaknya binatang pengganggu. Penyehatan ruang dan bangunan terihat masih kurang bersih yaitu ditemukannya sampah-sampah, lantai di ruang tunggu terminal kurang bersih, tempat sampah terminal tidak dilengkapi dengan penutup.

\section{Saran}

Untuk lebih meningkatkan terutama sanitasi di Terminal Mabu'un Kabupaten Tabalong, maka disarankan kepada :

1. Dinas Perhubungan

a. Melakukan pembersihan pada saluran air secara berkala setiap seminggu sekali oleh petugas kebersihan.

b. Melakukan pembersihan di lingkungan luar setiap dua kali dalam sehari oleh petugas kebersihan yaitu pagi hari dan siang hari serta memberikan penyuluhan pada penjual makanan agar tidak membuang sampah sembarangan.

c. Melakukan perbaikan halaman parkir yang berlobang agar tidak becek saat hari hujan.

d. Untuk upaya menjaga kebersihan disediakan tenaga cleaning service oleh Dinas Perhubungan khusus untuk ruang tunggu penumpang di terminal Mabu'un Kabupaten Tabalong.

a. Menambah jumlah tempat sampah di ruang tunggu Terminal Mabu'un Kabupaten Tabalong.

2. Dinas Kesehatan

a. Melakukan pemeriksaan sanitasi terminal minimal 6 bulan 1 kali untuk Terminal Mabu'un Kabupaten Tabalong.

b. Memberikan penyuluhan tentang penggunaan peralatan yang layak untuk digunakan.

\section{KEPUSTAKAAN}

1. Atmadi, Pingit Broto. 2007. Tinjauan Aspek Teknis Pembangunan Suatu Terminal. Jurnal Teodolita Vol 7 No.1 Juni 2007.

2. Kardadi. 2010. Terminal Penumpang dan Sistem Jaringan Angkutan Umum. Diakses 16 Februari 2013.

3. http://www/dephub.go.id. Transportai Darat. Diakses 20 Maret 2013.

4. Depkes RI. 2002. Pedoman Umum Hygiene Sarana dan Bangunan Umum. Direktorat Jenderal PPM \& PL. Jakarta

5. Fazerin, Maulana. 2011. Penerapan Sanitasi Terminal Keramat di Kota Barabai Tahun 2011. Karya Tulis Ilmiah. Poltekkes Kemenkes Banjarmasin Jurusan Kesehatan Lingkungan.

6. Veramida, Annida. 2012. Sanitasi Terminal Kabupaten Kotabaru Tahun 2012. Karya Tulis Ilmiah. Poltekkes Kemenkes Banjarmasin Jurusan Kesehatan Lingkungan.

7. Depkes RI. 1999. Kumpulan Formulir Pemeriksaan Kesehatan Lingkungan (Inspeksi Sanitasi) Bidang Penyehatan Tempat-tempat Umum. Penyehatan Lingkungan Pemukiman. Jakarta.

8. KEPMENKES

Nomor 829/Menkes/SK/VII/1999 tentang Persyaratan Perumahan dan Permukiman.

9. Sugiawan. 2002. Kesehatan Lingkungan. http://www.sugiawan.wordpress.com/ 2002/. Diakses 20 Maret 2013.

10. Santoso, Imam. 2011. Inspeksi Sanitasi. (Buku ajar tidak dipublikasikan).

11. Winarso, Hadi. 2010. Sanitasi Sarana Transportasi. http://www.hadiwinarsokesling.com/2010/01/sanitasi-saranatransportasi.html. Diakses 20 Februari 2010.

12. PERMENKES Nomor 718/Menkes/Per/XI/1987. Standar Kebisingan.

13. Chairyanti. 2006. Kualitas Kebersihan Peralatan Makan pada Rumah Makan di Wilayah Kerja Puskesmas Sei Besar Kota Banjarbaru Tahun 2006. Karya Tulis Ilmiah. Poltekkes Kemenkes Banjarmasin Jurusan Kesehatan Lingkungan. 